\title{
Treatment of dyeing wastewater including reactive dyes (Reactive Red RB, Reactive Black B, Remazol Blue) and Methylene Blue by fungal biomass
}

\author{
Ülküye Dudu Gül* \\ Bilecik Seyh Edebali University, Vocational School of Health Services, Department of Medical Laboratory Techniques, 11210 Gülümbe, Bilecik, Turkey
}

\begin{abstract}
The decolourisation potential of growing Rhizopus arrhizus fungal strain in liquid medium containing thiamine was investigated for the removal of anionic reactive dyes such as Reactive Red RB (RR), Reactive Black B (RBB) and Remazol Blue (RB) and a cationic basic dye Methylene Blue (MB). To determine the optimal pH value, $\mathrm{pH} 2$ to 6 was examined. Fungal growth was not observed at $\mathrm{pH}$ 2. Maximum fungal decolourisation ocurred at $\mathrm{pH} 3$ for anionic reactive dyes (RR, RBB, RB) and $\mathrm{pH} 6$ for cationic MB dye. The fungal dye bioremoval was associated with the surface charge of the fungus due to electrostatic interactions. Growing R. arrhizus strain decolourised $100 \%$ of RB in 2 days, $100 \%$ of RBB in 3 days, $71.83 \%$ of RR in 8 days at $\mathrm{pH} 3$ and $92.5 \%$ of $\mathrm{MB}$ in 8 days at $\mathrm{pH} 6$ at $100 \mathrm{mg} / \ell$ dye concentration. Results indicate that growing Rhizopus arrhizus is an effective candidate for removal of different types of dyes from textile effluents.
\end{abstract}

Keywords: Rhizopus arrhizus, wastewater treatment, decolourisation, textile dye

\section{INTRODUCTION}

Dyeing effluents are potentially problematic compounds because of their toxic and carcinogenic effects on aquatic biota and humans (Crini, 2006). It is well known that the treatment of dyeing wastewater is very difficult due to the complex aromatic structure and synthetic origin of most dyes (Hadibarata et al., 2012). Generally, synthetic dyes can be classified as anionic (direct, acid and reactive dyes), cationic (basic) and non-ionic (disperse) (Mishra and Tripathy, 1993). Reactive dyes are formed by the combination of azo-based chromophores with different types of reactive groups such as vinyl sulfone, chlorotriazine, trichloropyrimidine and difluorochloropyrimidine (Aksu, 2005). Reactive dyes are commonly used in textile industries because of their favourable characteristics of bright colour, water-fastness, and simple application techniques with low energy consumption (Aksu, 2005). Removal of reactive dyes is especially problematic because they can easily pass through conventional treatment systems and without much change (Zhao et al., 2005). Methylene Blue (MB) is a cationic basic thiazine dye extensively used in dyeing cottons (Aksu et al., 2010). MB dye can cause health problems in humans after inhalation (Cengiz and Cavas, 2008). It is important to treat dyeing wastewaters containing reactive dyes and Methylene Blue dye because of their harmful effects.

Physical and chemical methods, such as chemical coagulation/flocculation, ozonation, oxidation, ion exchange, irradiation, precipitation and adsorption are used for decolourisation of dyes (Ayed et al., 2011). These methods are not feasible techniques since they are very expensive and experience operational problems (Dönmez, 2002). Biological wastewater treatment is often the most economical and eco-friendly alternative, relative

\footnotetext{
To whom all correspondence should be addressed.

용 (+90-228) 214 1374; fax: (+90-228) 214 1017; e-mail: ulkuyedudu.gul@bilecik.edu.tr

Received 23 January 2013; accepted in revised form 15 August 2013.
}

to other physical and chemical processes (Davies et al., 2005). Microbial decolourisation methods, such as bioremoval by growing culture in medium and biosorption by (living or dead) microbial biomass, are commonly applied to the treatment of textile industry effluents because various microorganisms, such as bacteria, yeasts, algae and fungi, are able to remove different classes of dyes (Fu and Viraraghavan, 2001; Srinivasan and Viraraghavan, 2010).

The genus Rhizopus comprises of filamentous fungi extensively found in soil (Cardoso et al., 2012). The filamentous fungal strains are of great interest for biotechnological applications such as wastewater treatment because polymers are present in the structure of the cell wall which are responsible for the adsorption of dyes and other pollutants (Aksu, 2001). Studies have demonstrated the effective dye removal properties of dead R. arrhizus biomass (Aksu and Tezer, 2000; O'Mahony et al., 2002; Aksu and Karabayır, 2008). Bioremoval of dyes using growing $R$. arrhizus cultures is one of the more frequently reported emerging methods for decolourisation of textile dyes. Use of growing cultures for dye bioremoval processes has the advantage of avoiding separate biomass production processes, such as cultivation, harvesting, drying, processing and storage prior to use (Aksu and Dönmez, 2005).

This study aims to investigate the bioremoval potential of commonly available growing Rhizopus arrhizus culture for textile dyes such as Remazol Blue (RB), Reactive Black B (RBB), Reactive Red RB (RR) and Methylene Blue (MB), at batch-scale level, in order to assess application of this technique in an oxidation pond. The study also aimed to investigate the potential improvement of fungal decolourisation performance by adding thiamine to the growth medium. Although R. arrhizus is capable of utilising a variety of nutrients, thiamine was chosen due to its positive effect on fungal growth and decolourisation (Chung and Tzeng, 2004; Kirk et al., 1978; Glenn and Gold, 1983). This is the first report to date, and to our knowledge, that investigates the use of growing $R$. arrhizus culture in treating industrial wastewaters containing various types of dyes. 


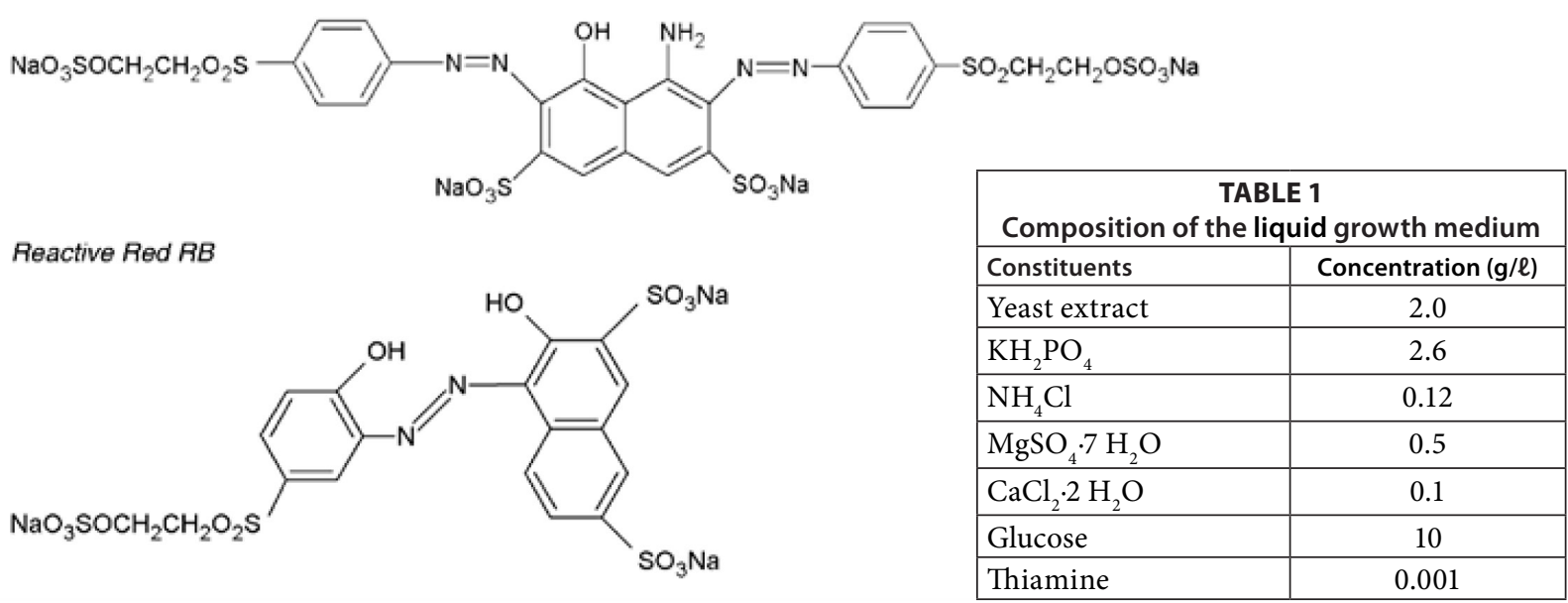<smiles>CN(C)c1ccc2nc3ccc(N(C)C)cc3[s+]c2c1</smiles>

Figure 1

Chemical structure of Reactive Black B, Reactive Red RB, Methylene Blue

\section{MATERIALS AND METHODS}

\section{Culture medium}

The filamentous fungus Rhizopus arrhizus (NRRL 1526) was obtained from the US Department of Agriculture Culture Collection. The pure cultures (Rhizopus arrhizus) were maintained on Potato Dextrose Agar (PDA) media, containing $39.0 \mathrm{~g} / \ell \mathrm{PDA}$ and dye, at $4^{\circ} \mathrm{C}$. PDA was purchased from Merck (1.10130) and the cultivation medium was autoclaved at $121^{\circ} \mathrm{C}$ for $15 \mathrm{~min}$.

The fungal cells were used in two ways to decolourise dyeing water: growing cells in liquid medium bioremoved dyes, and living cells biosorbed dyes. In order to compare the dye removal rate for growing and living cells, biosorption experiments using living cells were performed with RB dye only, which was maximally bioremoved by growing cells.

\section{Preparation of dye solutions}

Remazol Blue (RB), Reactive Black B (RBB) and Reactive Red RB (RR) were obtained from Aytemizler Textile Co., Turkey, in pure form. Methylene Blue (MB) (C.I: 52030) dye was supplied by Merck. Dyes were selected based on frequency of use in the local textile industries. The dye structures of Reactive Black B (RBB), Reactive Red RB (RR) and Methylene Blue (MB) are shown in Fig. 1 (from Pearce et al., 2003; CII, 2006; Gusmão et al., 2012). The structure of the Remazol Blue dye is not in the public domain. The dye stock solutions (RB, RBB and RR) were prepared by dissolving the powdered dyestuff in distilled water to obtain a final concentration of $2 \%(\mathrm{w} / \mathrm{v})$. A stock solution of Methylene Blue (MB) was prepared at $1.0 \mathrm{~g} / \ell$ concentration by dissolving the weighed amount in double-distilled water. Appropriate volumes of the stock solutions were added to the media.

\section{Dye bioremoval experiments with growing $R$. arrhizus in medium}

Dye bioremoval experiments with growing fungus were performed in liquid growth medium. The composition of the growth medium is given in Table 1 . The $\mathrm{pH}$ was adjusted to desired value with $0.1 \mathrm{M} \mathrm{NaOH}$ and $1 \mathrm{M} \mathrm{H}_{2} \mathrm{SO}_{4}$. The medium was autoclaved $\left(121^{\circ} \mathrm{C}\right.$ for $\left.15 \mathrm{~min}\right)$ and then a defined quantity of sterilised dye solution with a known concentration was added to the liquid growth medium. The fungal cells were inoculated twice into $250 \mathrm{~m} \ell$ Erlenmeyer flasks containing $100 \mathrm{~m} \ell$ of liquid medium at $30^{\circ} \mathrm{C}$.

Decolourisation experiments were performed with $100 \mathrm{m \ell}$ culture medium placed in $250 \mathrm{~m} \ell$ Erlenmeyer flasks. In order to examine the effect of initial $\mathrm{pH}$ and incubation time, initial $\mathrm{pH}$ was varied between 2, 3, 4, 5 and 6 for each dye (initial dye concentration: $100 \mathrm{mg} / \ell$ ) over 8 days at $30^{\circ} \mathrm{C}$. All of the experiments were carried out at least twice. The values used in calculations were mostly the arithmetic average of the experimental data.

A 3-m $\ell$ sample was taken daily from each flask. Samples were centrifuged by Med. Instruments MPW-351 R model centrifuge to remove suspended biomass and the concentration of dye in the supernatant was determined by reading absorbance at the maximum absorption peak for each dye: at $600 \mathrm{~nm}$ for Remazol Blue (RB), at $590 \mathrm{~nm}$ for Reactive Black B (RBB), at $495 \mathrm{~nm}$ for Reactive Red (RR) and at $663 \mathrm{~nm}$ for Methylene Blue (MB) The calibration curve of absorbance versus concentration for each dye solution was plotted. Absorbance measurements were done using a Shimadzu UV 2001 model spectrophotometer. Dye-containing liquid medium was used as the blank. For detemination of fungal growth, dry weight of fungal biomass was measured at the end of the incubation period. Dry weight of the fungal biomass was obtained by filtering the contents of each flask through pre-weighed filter paper, drying to a constant weight at $80^{\circ} \mathrm{C}$ overnight and measuring the dry weight of biomass. Dry weight was expressed in terms of grams of biomass per litre of culture.

\section{Dye biosorption experiments with living fungal cells}

To examine the biosorption of RB dye by R. arrhizus, living fungal cells were prepared. The fungal biomass was filtered from liquid medium ( $\mathrm{pH} 3$ ) after 2 days incubation period without dye. The cell samples were transferred into $250-\mathrm{m} \ell$ 


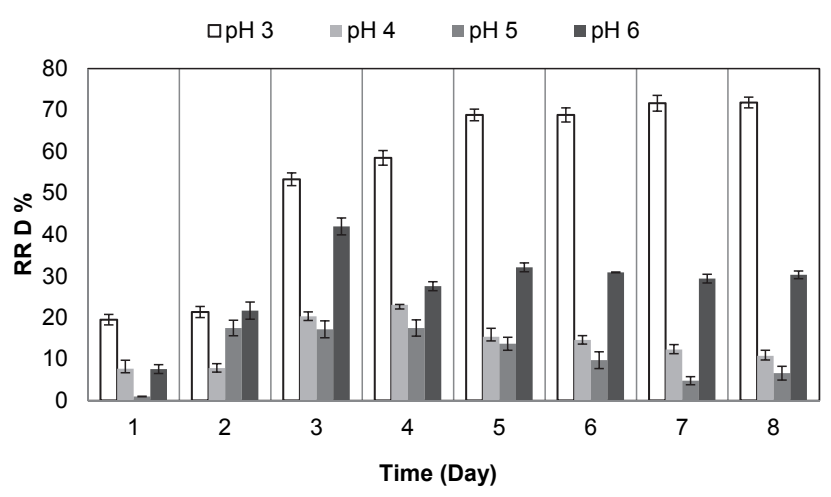

Figure 2

The effect of $\mathrm{pH}$ and incubation time on Reactive Red RB (RR) dye bioremoval (D\%) by growing $\mathrm{R}$. arrhizus in liquid medium with $100 \mathrm{mg} / \mathrm{l}$ dye at $30 \pm 1^{\circ} \mathrm{C}$

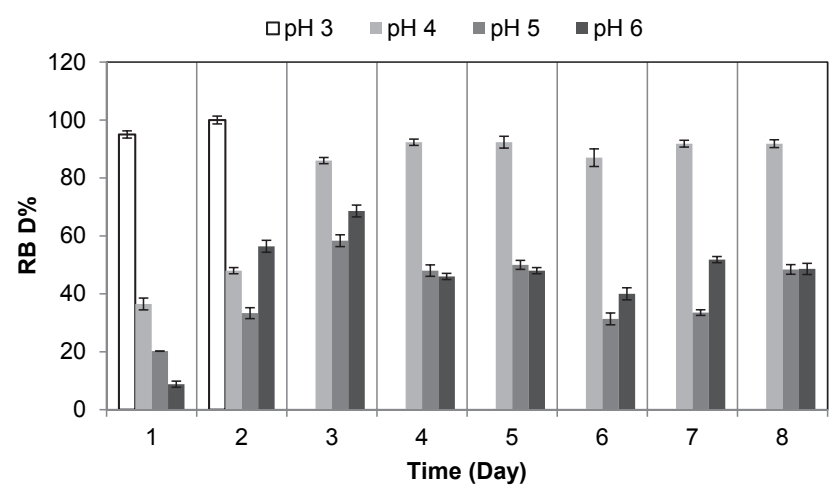

Figure 3

The effect of $p H$ and incubation time on Remazol Blue (RB) dye bioremoval (D\%) by growing R. arrhizus in liquid medium with $100 \mathrm{mg} / \mathrm{l}$ dye at $30 \pm 1^{\circ} \mathrm{C}$

Erlenmeyer flasks containing $100 \mathrm{~m} \ell$ distilled water with $100 \mathrm{mg} / \ell \mathrm{RB}$. Then, 3-m $\ell$ samples were taken every $2 \mathrm{~h}$ and centrifuged at $10000 \mathrm{r} / \mathrm{min}$ for $15 \mathrm{~min}$ in order to remove suspended biomass, and dye concentration in the supernatant was analysed spectrophotometrically (600 nm for RB) over a 48 -h period. The 100 -me distilled water flask containing only dye and surfactant without fungus was used as control.

\section{Analytical methods}

The percentage bioremoval of dye was calculated using the following equation:

$$
\text { Dye decolourisation }(\%)=\left(C_{o}-C_{f}\right) / C_{o} \times 100
$$

where:

$\mathrm{C}_{o}$ and $\mathrm{C}_{f}$ represent the initial and final dye concentrations $(\mathrm{mg} / \ell)$, respectively.

\section{RESULTS}

\section{Effect of $\mathrm{pH}$ and incubation time on dye bioremoval by growing fungal cells}

To investigate the effect of $\mathrm{pH}$ and incubation time on dye bioremoval by growing $R$. arrhizus, the medium $\mathrm{pH}$ was varied to $\mathrm{pH} 2,3,4,5$ and 6 for all of the dyes under investigation.

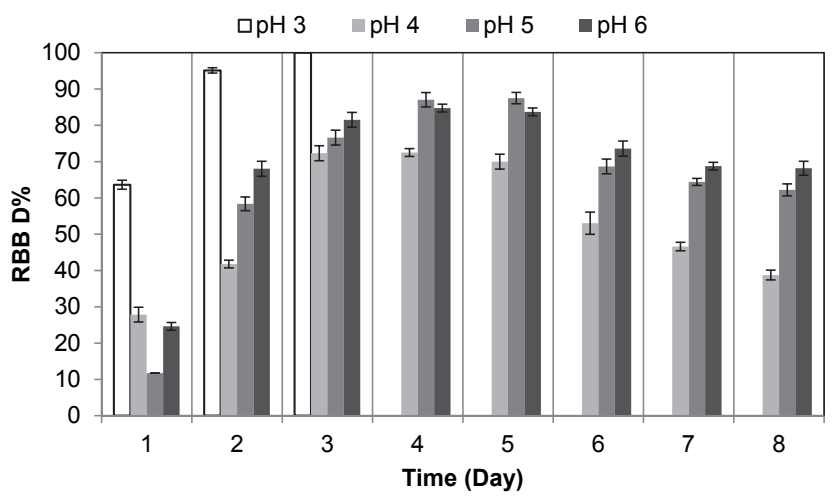

Figure 4

The effect of $\mathrm{pH}$ and incubation time on Reactive Black (RBB) dye bioremoval (D\%) by growing $\mathrm{R}$. arrhizus in liquid medium with $100 \mathrm{mg} / \mathrm{l}$ dye at $30 \pm 1{ }^{\circ} \mathrm{C}$

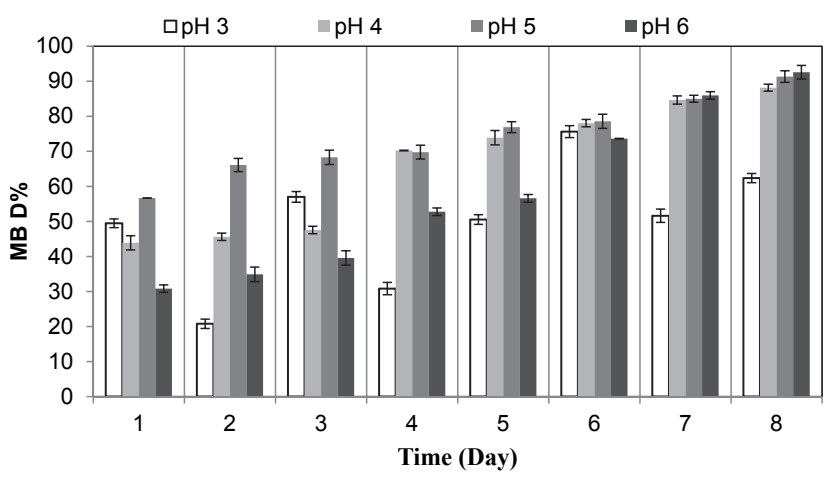

Figure 5

The effect of $\mathrm{pH}$ and incubation time on Methylene Blue (MB) dye bioremoval (D\%) by growing $\mathrm{R}$. arrhizus in liquid medium with $100 \mathrm{mg} / \mathrm{l}$ dye at $30 \pm 1^{\circ} \mathrm{C}$

Fungal strain was inoculated into Erlenmeyer flasks containing $100 \mathrm{~m} \ell$ liquid medium with $100 \mathrm{mg} / \ell$ dye and incubated for 8 days. No fungal growth occurred at $\mathrm{pH} 2$. Maximum RR decolourisation (71.83\% after 8 days) occured at $\mathrm{pH} 3$, as (Fig. 2). Decolourisation rates were very similar between 7 and 8 days of incubation. The fungal strain decolourised $100 \%$ of $100 \mathrm{mg} / \ell \mathrm{RB}$ at $\mathrm{pH} 3$ after 2 days of incubation (Fig. 3) and removed $100 \%$ of $\mathrm{RBB}$ at $\mathrm{pH} 3$ after 3 days (Fig. 4). MB (100 $\mathrm{mg} / \ell$ growing) removal by $R$. arrhizus strain was $92.5 \%$ at $\mathrm{pH} 6$ after 8 days (Fig. 5).

\section{Effect of pH on biosorption of dye by living fungal cells}

The effect of $\mathrm{pH}$ on biosorption of Remazol Blue (RB) by $R$. arrhizus was examined in Erlenmeyer flasks contained $100 \mathrm{~m} \ell$ double-distilled water with $100 \mathrm{mg} / \ell \mathrm{RB}$ at $\mathrm{pH} 3,4,5$ and 6 over $48 \mathrm{~h}$. Maximum dye biosorption ( $49.7 \%$ in $24 \mathrm{~h}$ ) occurred at $\mathrm{pH} 3$ (Fig. 6). There was no significant change in biosorption (B\%) of RB by R. arrhizus after $24 \mathrm{~h}$.

\section{DISCUSSION}

RR, RB, RBB bioremoval by Candida tropicalis has been demonstrated to achieve a removal rates of $87.9 \%$ at $103.1 \mathrm{mg} / \ell \mathrm{RR}$, $98.8 \%$ at $91.3 \mathrm{mg} / \ell \mathrm{RB}$, and $98.3 \%$ at $101.7 \mathrm{mg} / \ell \mathrm{RBB}$ concentration, in 6 days at $\mathrm{pH} 3$ (Dönmez, 2002). Saccaromyces cerevisae decolourised $74.3 \%$ of $102.5 \mathrm{mg} / \ell \mathrm{RR}$ in 16 days, $91.2 \%$ of 


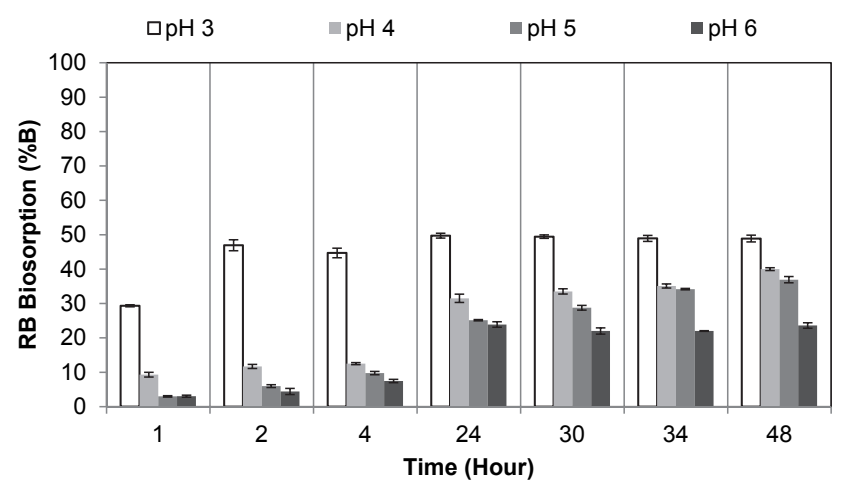

Figure 6

The effect of $p H$ and incubation time on Remazol Blue (RB) Biosorption (B\%) by living $\mathrm{R}$. arrhizus with $100 \mathrm{mg} / \mathrm{l}$ dye at $30 \pm 1^{\circ} \mathrm{C}$

$78.9 \mathrm{mg} / \ell \mathrm{RB}$ in 11 days, $88.4 \%$ of $94.3 \mathrm{mg} / \ell \mathrm{RBB}$ in 14 days at pH 3 (Aksu, 2003). Çetin et al. (2008) have reported that mixed culture removed about $20 \%$ of $98.3 \mathrm{mg} / \ell \mathrm{RR}, 24 \%$ of $95.8 \mathrm{mg} / \ell$ $\mathrm{RB}$ and $26 \%$ of $97.4 \mathrm{mg} / \ell \mathrm{RBB}$ after 3 days. Recently, Namdhari et al. (2012) showed that Reactive Blue decolourisation was 95.13\%, $93.01 \%$ and $82.62 \%$ by Aspergillus allhabadii, A. suphureus and $A$. niger, respectively, in 10 days. In this study it was found that $R$. arrhizus decolourised $100 \%$ of $100 \mathrm{mg} / \ell \mathrm{RB}$ in 2 days and $100 \%$ of $100 \mathrm{mg} / \ell \mathrm{RBB}$ in 3 days at $\mathrm{pH} 3$..

Dyes belonging to different classes were used in this study in order to compare dye-type effects on the bioremoval properties of R. arrhizus. Remazol Blue and Reactive Black B were able to be decolourised to a greater extent (100\% removal), while Reactive Red was only able to be bioremoved to a lesser extent in a short incubation period (Table 2). Remazol Blue appeared to be the dye most effectively bioremoved by the fungus. This difference in bioremoval was due to the smaller molecular structure of Remazol Blue relative to the other reactive dyes (Dönmez, 2002).

$R$. arrhizus decolourised anionic reactive dyes more effectively than the cationic thiazine dye. Fungal decolourisation of anionic dyes occurred at low $\mathrm{pH}$ values ( $\mathrm{pH} 3$ ), but cationic dye bioremoval was maximum at $\mathrm{pH} 6$ (Table 2). Medium $\mathrm{pH}$ had a significant effect on decolourisation, associated with the chemical properties of the dyes and fungal surface. The $\mathrm{pH}$ value of the medium influenced the bioremoval properties of the fungal biomass (Aksu and Tezer, 2000). The bioremoval behaviour of the fungal biomass was mainly linked to the composition of the cell wall, which was considered as the primary site of bioavalibility. The $\mathrm{pH}$ dependence of dye removal was related to protonation or deprotonation of the functional groups of the biopolymers on the biomass surface and the ionisation potential of complex dye molecules in solution (Maurya et al., 2006). The fungal cell walls had both cation- and anion-exchange properties. The cell walls contained amino groups with low $p K_{a}$ values and cation exchange groups with high $p K_{a}$ values, which enabled a cell wall to be a natural anion and cation exchanger depending on the environmental conditions (Feofilova, 2010). The electrical charge of the fungal surface can be measured in the form of a zeta potential isoelectric point, depending on the solution pH (Aksu and Karabayır, 2008). The surface charge on each fungal biomass is predominantly positive at low $\mathrm{pH}$ values, due to the presence of ionised groups such as carboxyl, phosphate, and amino groups (Aksu and Tezer, 2000). The surface of fungal cells charged positively at $\mathrm{pH}$ values below the isoelectronic point due to protonation of nitrogen-containing functional groups such as amines or imidazoles that are major adsorption sites for dye removal ( $\mathrm{Wu}$ and $\mathrm{Yu}, 2006)$.

The isoelectric point of $R$. arrhizus has been shown to be below pH 5.5 (Tobin and Cooper, 1984). The surface charge of R. arrhizus was positive at $\mathrm{pH}<5.5$, and anionic reactive dye removal maximum at $\mathrm{pH} 3$, because of electrostatic interactions (Table 2). The surface charge became negative at $\mathrm{pH}>5.5$ and cationic MB dye removal was maximal at $\mathrm{pH} 6$ (Table2). Recently, it has been reported that the filamentous fungus R. arrhizus has chitin and chitosan polymers in the structure of its cell wall (Cardoso et al., 2012). Chitin/chitosan is a component of fungal cell walls and the major site of sorption (Fu and Viraraghavan, 2001). Chatterjee et al. (2007) studied the sorption capacity of chitosan for the anionic dye Congo Red, as well as the ionic interaction between Congo Red and chitosan, and concluded that the dye removal capacity of chitosan decreased with an increase in the initial $\mathrm{pH}$ value. The dye removal mechanism was related to the presence of chitosan as a component of the fungal cell, and electrostatical interactions between chitosan and dye molecules, depending on environmental conditions.

The difference in dye removal related to removal mechanism was investigated by comparing the removal rates for growing cell biomass in liquid medium and living cell biomass in water. MB sorption by dead $R$. arrhizus biomass was $12.4 \%$; growing $R$. arrhizus in liquid medium with thiamine decolourised $56.7 \% \mathrm{MB}$ in $24 \mathrm{~h}$ (Table 3). RB biosorption by living culture in water was $62.1 \%$ but decolourisation by growing culture in liquid media with thiamine was $100 \%$ in $48 \mathrm{~h}$ (Table 3). Dye bioremoval rate by growing biomass was higher than dye biosorption by living and dead biomass in the same incubation time.

Decolourisation rate changed according to the composition of the growth medium ingredients for a particular culture. As seen in Table 3, the growing fungal biomass in liquid media with thiamine removed $100 \%$ of RB in $48 \mathrm{~h}$ but growing fungal biomass in molasses media decolourised $39.2 \%$ of RB in $120 \mathrm{~h}$ (Gül and Dönmez, 2012). It is assumed that the difference in decolourisation rate was related to the composition of the medium, and ingredients such as thiamine, carbon and

TABLE 2

The effect of dye type on fungal dye bioremoval (D\%) in liquid medium at $30 \pm 1{ }^{\circ} \mathrm{C}\left(\mathrm{C}_{\text {odye: }}\right.$ Initial dye concentration)

\begin{tabular}{|l|l|l|c|c|c|c|}
\hline Dye & Type & $\begin{array}{l}\text { Chemical } \\
\text { character }\end{array}$ & $\begin{array}{c}\mathbf{C}_{\text {odye }} \\
(\mathbf{m g} / \mathbf{l})\end{array}$ & $\begin{array}{c}\text { Maximum } \\
\mathrm{D} \%\end{array}$ & pH & $\begin{array}{c}\text { Time } \\
(\text { day) }\end{array}$ \\
\hline Reactive Red (RR) & Reactive & Anionic & 100 & 71.83 & 3 & 8 \\
\hline Reactive Blue (RB) & Reactive & Anionic & 100 & 100 & 3 & 2 \\
\hline Reactive Black B (RBB) & Reactive & Anionic & 100 & 100 & 3 & 3 \\
\hline Methylene Blue (MB) & Thiazine & Cationic & 100 & 92.5 & 6 & 8 \\
\hline
\end{tabular}




\section{TABLE 3}

Dye bioremoval (D\%) by growing R. arrhizus (Ra) in media and biosorption in water of Remazol Blue (RB) and Methylene Blue (MB); this study and values from the literature)

\begin{tabular}{|l|l|l|l|c|c|l|}
\hline Fungus & Dye & $\begin{array}{l}\mathbf{C}_{\text {odye }} \\
(\mathbf{m g} / \mathbf{l})\end{array}$ & Mechanism & D\% & Time (h) & Reference \\
\hline $\mathrm{Ra}$ & $\mathrm{MB}$ & 50 & Biosorption in water (dead cell) & 12.4 & 24 & Aksu et al., 2010 \\
\hline $\mathrm{Ra}$ & $\mathrm{RB}$ & 100 & Growing in molasses media & 39.2 & 120 & Gül and Dönmez, 2011 \\
\hline $\mathrm{Ra}$ & $\mathrm{RB}$ & 100 & Biosorption in water (living cell) & 62.1 & 48 & This study \\
\hline $\mathrm{Ra}$ & $\mathrm{RB}$ & 100 & Growing in liquid media with thiamine & 100 & 48 & This study \\
\hline $\mathrm{Ra}$ & $\mathrm{MB}$ & 100 & Growing in liquid media with thiamine & 56.7 & 24 & This study \\
\hline
\end{tabular}

nitrogen sources. In molasses medium carbon and nitrogen sources were sucrose and ammonium sulphate (Gül and Dönmez, 2012). The liquid medium, which was used in this study, contained glucose and yeast extract as carbon and nitrogen source. Hadibarata and Kristati (2011) studied the effect of carbon source on removal of Remazol Brillant Blue $\mathrm{R}$ (RBBR) and showed that maximum RBBR decolourisation (100\% in 6 days) was observed with glucose (as carbon source). In the current study the vitamin thiamine was used as a component of the liquid medium. It has been reported that adding thiamine to the medium contributes to fungal growth (Chung and Tzeng, 2004). Thiamine is required for lignin metabolism and growth of fungus (Kirk et al., 1978). Decolourisation and ligninolytic activity of fungus is known to be correlated (Glenn and Gold, 1983). According to the results of this study, using thiamine in the medium increased fungal growth, with the dry weight of $R$. arrhizus biomass recorded as $2.604 \mathrm{mg} / \ell$ in $100 \mathrm{~m} \ell$ liquid medium with thiamine, $100 \mathrm{mg} / \ell \mathrm{RB}$, at $\mathrm{pH} 3$ after 2 days. Gül and Dönmez (2012) reported that growing $R$. arrhizus biomass in mollasses medium with $100 \mathrm{mg} / \ell \mathrm{RB}$ resulted in $2.01 \mathrm{mg} / \ell$ dry weight at $\mathrm{pH} 3$ after 3 days. Addition of components to the growth medium, such as glucose, yeast extract and thiamine, enhanced both microbial growth and decolourisation.

\section{CONCLUSION}

The results obtained show that growing $R$. arrhizus in liquid media with thiamine is able to remove all of the selected dyes, but to differing extents. Addition of thiamine to the growth medium had a positive effect on fungal decolourisation. The bioremoval efficiency for 4 dyes differed significantly depending on the structure of the dye. Decolourisaion of RB and RBB $R$. arrhizus was $100 \%$ in short incubation periods. The shortened incubation period enables the energy savings and a reduction in energy costs for the treatment of dyeing wastewater. The fungus also removed $92.5 \%$ of cationic Methylene Blue dye.

From the above results, it was concluded that $R$. arrhizus can efficiently remove various types of dyes, including reactive and basic dyes. Future work will concentrate on using the fungal biomass in the development of a textile effluent treatment system.

\section{REFERENCES}

AKSU Z and TEZER S (2000) Equilibrium and kinetic modelling of biosorption of Remazol Black B by Rhizopus arrhizus in a batch system: effect of temperature. Process Biochem. 36 431-435.

AKSU Z (2001) Biosorption of reactive dyes by dried activated sludge: equilibrium and kinetic modelling. Biochem. Eng. J. 7 79-84.
AKSU Z (2003) Reactive dye bioaccumulation by Saccharomyces cerevisiae. Process Biochem. 38 1437-1444.

AKSU Z (2005) Application of biosorption for the removal of organic pollutants: a review. Process Biochem. 40 997-1026.

AKSU Z and DÖNMEZ G (2005) Combined effects of molasses sucrose and reactive dye on the growth and dye bioaccumulation properties of Candida tropicalis. Process Biochem. $402443-2454$.

AKSU Z and KARABAYIR G (2008) Comparison of biosorption properties of different kinds of fungi for the removal of Gryfalan Black RL metal-complex dye. Bioresour. Technol. 99 7730-7741.

AKSU Z, ERTUĞRUL S and DÖNMEZ G (2010) Methylene Blue biosorption by Rhizophus arrhizus: Effect of SDS (sodium dodecylsulfate) surfactant on biosorption properties. Chem. Eng. J. 158 474- 481 .

AYED L, ACHOUR S and BAKHROUF A (2011) Application of the mixture design to decolourise effluent textile wastewater using continuous stirred bed reactor. Water SA 37 21-26.

CARDOSO A, LINS CIM, RAMOS DOS SANTOS E, SİLVA MCF and CAMPOS-TAKAKİ GM (2012) Microbial enhance of chitosan production by Rhizopus arrhizus using agroindustrial substrates. Molecules 17 4904-4914.

CENGİZ S and CAVAS L (2008) Removal of methylene blue by invasive marine seaweed: Caulerpa racemosa var. cylindracea. Bioresour. Technol. 99 2357-2363.

CII (COLOR INDEX INTERNATIONAL) (2006) Colour Index International. 4th Edition (Online). Society of Dyers and Colorists in conjunction with the American Association of Textile Chemists and Colorists. URL: http://www.colour-index.com/.

CHATTERJEE S, CHATTERJEE BP and GUHA AK (2007) Adsorptive removal of congo red, a carcinogenic textile dye, by chitosan hydrobeads: binding mechanism, equilibrium and kinetics. Colloid Surf. A 299 146-152.

CHUNG K and TZENG DD (2004) Nutritional requirements of the edible gall-producing fungus Ustilago esculenta. J. Biol. Sci. 4 $246-252$.

CRINII G (2006) Non-conventional low-cost adsorbents for dye removal: A review. Bioresour. Technol. 97 1061-1085.

ÇETIN D, DÖNMEZ S and DÖNMEZ G (2008) The treatment of textile wastewater including chromium(VI) and reactive dye by sulfate-reducing bacterial enrichment. J. Environ. Manage. 88 76-82.

DAVIES LC, CARIAS CC, NOVAIS JM and MARTINS-DIAS S (2005) Phytoremediation of textile effluents containing azo dye by using Phragmites australis in a vertical flow intermittent feeding constructed wetland. Ecol. Eng. 25 594-605.

DÖNMEZ G (2002) Bioaccumulation of the reactive textile dyes by Candida tropicalis growing in molasses medium. Enzyme Microbiol. Technol. 30 363-366.

FEOFILOVA EP (2010) The fungal cell wall: Modern concepts of its composition and biological function. Microbiology 79 711-720.

FU Y and VIRARAGHAVAN T (2001) Fungal decolourisation of dye wastewaters: a review. Bioresour. Technol. 79 251-262.

GLENN JK and GOLD MH (1983) Decolourisation of several polymeric dyes by the lignin-degrading basidiomycete Phanerochaete chrysosporium. Appl. Environ. Microbiol. 45 1741-1747. 
GUSMAO KAG, GURGEL LVA, MELO TMS and GIL LF (2012) Application of succinylated sugarcane bagasse as adsorbent to remove methylene blue and gentian violet from aqueous solutions Kinetic and equilibrium studies. Dyes Pigments 92 967-974.

GÜL ÜD and DÖNMEZ G (2012) Comparison of the dye removal activity of systems contained surfactants and fungus. J. Chil. Chem. Soc. 57 1170-1173.

GÜL ÜD and DÖNMEZ G (2011) Effect of surfactants on Remazol Blue bioremoval capacity of growing Rhizopus arrhizus strain in molasses medium. Fresenius Environ. Bull. 20 2677-2683.

HADIBARATA T and KRISTANTI R (2012) Effect of environmental factors in the decolourisation of Remazol Brillant Blue R by Polyporus sp. S133. J. Chil. Chem. Soc. 57 1095-1998.

KIRK K, SCHULTZ E, CONNORS WJ, LORENZ LF and ZEIKUS JG (1978) Influence of culture parameters on lignin metabolism by Phanerochaete chrysosporium. Arch. Microbiol. 117 277-285.

MAURYA NS, MITTAL AK, CORNEL P and ROTHER E (2006) Biosorption of dyes using dead macro fungi: effect of dye structure, ionic strength and pH. Bioresour. Technol. 97 512-521.

MISHRA G and TRIPATHY M (1993) A critical review of the treatments for decolourization of textile effluent. Colourage 40 35-38.
NAMDHARI BS, ROHILLA SK, SALAR RK, GAHLAWAT SK, BANSAL P and SARANA K (2012) Decolourisation of Reactive Blue MR, using Aspergillus species isolated from textile waste water. J. Biol. Sci. $124-29$.

SRINIVASAN A and VIRARAGHAVAN T (2010) Decolourisation of dye wastewaters by biosorbents: A review. J. Environ. Manage. 91 1915-1929.

O'MAHONY T, GUIBAL E and TOBIN JM (2002) Reactive dye biosorption by Rhizopus arrhizus biomass. Enzyme Microbiol. Technol. 31 456-463.

PEARCE CI, LOYD JR and GUTHRIE JT (2003) The removal of color from textile wastewater using whole bacterial cells: a review. Dyes Pigments 58 179-196.

TOBIN JM, COOPER DG and NEUFELD RJ (1984) Uptake of metal ions by Rhizopus arrhizus biomass. Appl. Environ. Microbiol. 47 821-824.

WU J and YU H-Q (2006) Biosorption of 2,4-dichlorophenol from aqueous solution by Phanerochaete chrysosporium biomass: isotherms, kinetics and thermodynamics. J. Hazardous Mater. 137 498-508.

ZHAO G, LI M, HU Z and HU H (2005) Dissociation and removal of complex chromium ions contained in dye wastewaters. Sep. Purif. Technol. 43 227-232. 